\title{
PENGARUH LATIHAN FISIK TERSTRUKTUR TERHADAP PENURUNAN KADAR KOLESTROL PADA PASIEN HIPERTENSI DI RS GRANDMED LUBUK PAKAM
}

\section{Mifthahul Zannah ${ }^{1 *}$, Tati Murni Karokaro², Ida Yolanda², Rosita Ginting ${ }^{2}$, Abdi Lestari Sitepu ${ }^{3}$}

\author{
${ }^{1}$ Program Studi Pendidikan Profesi Fisioterapis Program Profesi Institut Keseharan \\ Medistra Lubuk Pakam \\ ${ }^{2}$ Program Studi Keperawatan Program Sarjana Institut Keseharan Medistra Lubuk Pakam \\ ${ }^{3}$ Program Studi Keperawatan Diploma III Institut Keseharan Medistra Lubuk Pakam
}

\author{
Jl. Sudirman No. 38 Lubuk Pakam, Kab. Deli Serdang \\ Sumatera Utara - Indonesia \\ *email korespondensi author : mfthlzannah@gmail.com
}

DOI $10.35451 /$ jpk.v1i1.704

\begin{abstract}
Abstrak
Hipertensi dan peningkatan kolesterol merupakan dua kondisi yang kontinu. Kadar kolesterol dalam tubuh merupakan salah satu faktor terpenting untuk menentukan risiko seseorang menderita penyakit arteri jantung. Untuk itu perlu diberikan latihan fisik terstruktur berupa olahraga teratur, selain dapat mengurangi stres juga dapat menurunkan berat badan, membakar lebih banyak lemak dalam darah dan memperkuat otot jantung. Untuk bisa melakukan olahraga ringan, tidak perlu datang ke tempat latihan khusus, karena program terbaik adalah yang Anda nikmati dan bisa berlangsung secara rutin. Metode: Penelitian ini menggunakan metode eksperimen kuantitatif dengan menggunakan desain post-test with control group (pretest-posttest with control group) dengan jumlah sampel 15 orang. Pengambilan sampel dilakukan dengan teknik purposive sampling menggunakan rumus Isac dan Mikael, penelitian dilakukan pada bulan April 2021. Hasil: Dari hasil penelitian didapatkan pada kelompok eksperimen nilai $p$ value $0,000(<0,05)$ dan pada kelompok kontrol $p$ value 0,001 (<0,05). Sehingga dapat disimpulkan bahwa kelompok eksperimen memberikan pengaruh yang lebih baik dibandingkan kelompok kontrol pada pasien hipertensi di RSU Grandmed Lubuk Pakam tahun 2021. Untuk itu diharapkan perawat di RSU Grandmed Lubuk Pakam dapat meningkatkan pelayanan di bidang non farmakologi khususnya untuk penderita hipertensi yang menderita hiperkolesterolemia yang dapat diatasi dengan pemberian intervensi berupa latihan fisik terstruktur.
\end{abstract}

Kata kunci: Latihan fisik terstruktur, Kadar Kolesterol, Hipertensi

\footnotetext{
Abstract

Hypertension and elevated cholesterol are two continuous conditions. Cholesterol level in the body is one of the most important factors to determine a person's risk of suffering from heart artery disease. Therefor it is necessary to provide Structured Physical Exercise in the form of regular exercise, in addition to reducing stress, it can
} 
Received: 28 May 2021 :: Accepted: 12 June 2021 :: Published: 30 June 2021

also lose weight, burn more fat in the blood, and strengthen the heart muscle. To be able to do light exercise, you don't need to come to a special training ground, because the best program is one that you enjoy and can take place regularly. Methods: This study used a quantitative experimental method using post-test design with a control group (pretest-posttest with control group) with a sample size of 15 people. Sampling was used with purposive sampling technique using the Isac and Mikael formulas, the study was used in April 2021. Results: From the research results found in the experimental group the $p$ value was $0.000 \leq 0.05$ and in the control group the $p$ value was $0.001 \leq 0.05$. So it can be concluded that the experimental group gives a better effect than the control group on hypertension patients at Grandmed Lubuk Pakam Hospital in 2021. Therefor it is hoped that nurses at Grandmed Lubuk Pakam Hospital can improve services in non-pharmacological fields, especially for hypertension patients who suffering from hypercholesterolemia which can be overcome by giving intervention in the form of structured physical exercise.

Keywords: Structured Physical Exercise, Cholesterol Levels, Hypertension

\section{Pendahuluan}

Hipertensi dan peningkatan kolesterol merupakan dua keadaan yang berkesinambungan. Menurut Fryer 2010 melalui survey penyakit kronis yang diderita oleh masyarakat Amerika merupakan penyakit Hipertensi yang disertai dengan hiperkolesterolemia. Lebih dari 55\% responden yang diteliti menunjukkan tanda dan gejala Hipertensi yang disertai dengan hiperkolesterolemia. Prevalensi hiperkolesterolemia di dunia sekitar 45\%, di Asia Tenggara sekitar $30 \%$ dan di Indonesia 35\% Sementara Persentase Pengunjung Posbindu PTM dan Puskesmas yang memiliki kolesterol tinggi di Provinsi Sumatera Utara Tahun 2016 sebanyak 235 orang atau sebesar 47,6\% (Fryer, 2010 \& Kemenkes RI, 2017; Balitbangkes, 2013; WHO, 2019).

Kadar kolesterol dalam tubuh adalah merupakan faktor utama untuk menetukan seseorang apakah seseorang tersebut menderita penyakit pembuluh darah jantung. Ada beberapa faktor yang terbukti melalui penelitian dapat mempengaruhi kadar kolesterol dalam darah antara lain usia, berat badan, pola makan, aktivitas fisik, merokok, stress, dan faktor keturunan (Yovina 2012).

Hipertensi dapat tidak terjadi pada individu dengan meminimalkan bahkan menghindari beberapa hal dengan berbagai cara yaitu membiasakan pola hidup yang baik seperti istirahat yang cukup, olah raga yang teratur, tidak stress, pikiran yang tenang, tidak mengkonsumsi kafein maupun alkohol, pola makan yang baik dengan menghindari ataupun mengurangi makanan yang mengandung lemak tinggi, tinggi kalori, berminyak, kolesterol, santan garam berlebihan (Tilong dalam Fajar, 2015).

Olahraga yang teratur dapat mengakibatkan kurangnya stres serta turunnya berat badan, terjadinya proses pembakaran lemak dalam darah, dan memperkuat otot jantung. Untuk dapat melakukan olahraga ringan tidak perlu datang ke tempat latihan khusus, karena program terbaik adalah latihan yang disenangi dan dapat berlangsung secara teratur, kegiatan sehari hari yang di jalani seperti berjalan santai, olahraga ringan dan bersepeda (Rahadiyanti, 2013). 
Received: 28 May 2021 :: Accepted: 12 June 2021 :: Published: 30 June 2021

Banyak penelitian yang telah membuktikan bahwa ada hubungan yang nyata antara latihan dan pengontrolan penyakit hiperkolesterolemia. Latihan dengan kualitas rendah sangat baik bagi penderita hiperkolesterolemia pada pasien hipertensi usia muda sampai dengan usia tua. Untuk mendapatkan manfaat kesehatan aktivitas fisik sebaiknya dilakukan 30 menit perhari (Kemenkes, 2017)

Hasil survei data pasien hipertensi yang di rawat inap di RS GRANDMED Lubuk Pakam tahun 2020 sebanyak 63 orang, dan sebanyak 39 orang pasien rawat inap di RS Grandmed Lubuk Pakam sudah menderita Penyakit Jantung Koroner (PJK) dan Hipertensi, diantaranya 23 laki-laki dan 16 perempuan serta mayoritas dari mereka sudah menduduki usia lanjut. Oleh karena itu perlu dikembangkan suatu alternatif latihan yang murah, aman, menyenangkan, tidak terlalu banyak menyita perhatian, tenaga, waktu dan efektif untuk memperbaiki profil lipid darah.

\section{Metode Penelitian}

Penyuluhan

dilaksanakan di poliklinik penyakit dalam Rumah Sakit Grandmed Lubuk Pakam, sampel yang diambil adalah seluruh pasien yang menderita hipertensi yaitu 15 orang. Penyuluhan yang dilakukan untuk melihat penurunan kadar kolesterol yaitu dengan menginformasikan langsung kepada pasien hipertensi mengenai Latihan terstruktur dengan edukasi, membagikan leaflet dan melakukan analisis data sebelum dan sesudah diberikan edukasi. Pasien yang menjadi sasaran penyuluhan ini merupakan pasien hipertensi.

\section{Hasil dan Pembahasan \\ a. Hasil}

Berdasarkan tabel 1 menunjukkan bahwa responden yang berjenis kelamin laki-laki sebanyak 9 orang $(60 \%)$ dan perempuan sebanyak 6 orang (40\%).

Tabel 1 : Karakteristik responden berdasarkan jenis kelamin

\begin{tabular}{cccc}
\hline No & $\begin{array}{c}\text { Karakteristik } \\
\text { Jenis } \\
\text { Kelamin }\end{array}$ & $\begin{array}{c}\text { Frekuensi } \\
(\mathrm{f})\end{array}$ & $\begin{array}{c}\text { Persen } \\
\text { tase } \\
(\%)\end{array}$ \\
\hline 1 & Laki-laki & 9 & 60 \\
\hline 2 & Perempuan & 6 & 40 \\
\hline & Total & 15 & 100 \\
\hline
\end{tabular}

Berdasarkan table 2 menunjukkan bahwa umur responden yang berusia 50-59 tahun yaitu 10 orang $(66,7 \%)$ dan yang berusia 60-69 tahun sebanyak 5 orang $(33,3 \%)$.

Tabel 2 : Karakteristik responden berdasarkan usia

\begin{tabular}{cccc}
\hline No & $\begin{array}{c}\text { Karakteristik } \\
\text { Jenis Usia }\end{array}$ & $\begin{array}{c}\text { Frekuensi } \\
\text { (f) }\end{array}$ & $\begin{array}{c}\text { Persen } \\
\text { tase } \\
(\%)\end{array}$ \\
\hline 1 & $50-59$ & 10 & 66,7 \\
\hline 2 & $60-69$ & 5 & 33,3 \\
\hline & Total & 15 & 100 \\
\hline
\end{tabular}

Berdasarkan tabel 3 menunjukkan bahwa jenis obat Hipertensi menggunakan Amlodipin $5 \mathrm{mg}$ sebanyak 12 orang (80\%) dan yang menggunakan Captropil 25mg sebanyak 3 orang (20\%).

Tabel 3 : Karakteristik responden berdasarkan jenis obat hipertensi

\begin{tabular}{cccc}
\hline No & $\begin{array}{c}\text { Karakteristik } \\
\text { Jenis Obat } \\
\text { Hipertensi }\end{array}$ & $\begin{array}{c}\text { Frekuensi } \\
\text { (f) }\end{array}$ & $\begin{array}{c}\text { Persen } \\
\text { tase } \\
(\%)\end{array}$ \\
\hline 1 & $\begin{array}{c}\text { Amlodipin } \\
5 \mathrm{mg}\end{array}$ & 12 & 80 \\
\hline 2 & $\begin{array}{c}\text { Captropil 25 } \\
\text { mg }\end{array}$ & 3 & 20 \\
\hline & Total & 15 & 100 \\
\hline
\end{tabular}

Berdasarkan Tabel 4 diatas terlihat bahwa rata-rata post-test pada 
Received: 28 May 2021 :: Accepted: 12 June 2021 :: Published: 30 June 2021

kelompok eksperimen yang diberikan latihan fisik terstruktur sebesar 216,67 dengan standart deviasi 12,549 hasil tertinggi 238 dan hasil terendah 204. Nilai rata-rata hasil post-test kelompok kontrol yang tidak diberikan Latihan Fisik Terstruktur sebesar 227,67 dengan standar deviasi 11,183 hasil tertinggi 241 dan hasil terendah 210.

Tabel 4: uji rata-rata pretest - posttest

\begin{tabular}{|c|c|c|c|c|c|}
\hline & $\mathrm{N}$ & $\begin{array}{c}\text { Minu } \\
\mathrm{mu} \\
\mathrm{m}\end{array}$ & $\begin{array}{c}\text { Ma } \\
\text { Xi } \\
\text { Mum }\end{array}$ & Mean & SD \\
\hline $\begin{array}{l}\text { Pre-Test } \\
\text { Eksperi } \\
\text { men }\end{array}$ & 6 & 219 & 252 & $\begin{array}{c}234,3 \\
3\end{array}$ & 11,361 \\
\hline $\begin{array}{l}\text { Post- } \\
\text { Test } \\
\text { Eksperi } \\
\text { men }\end{array}$ & 6 & 204 & 238 & $\begin{array}{c}216,6 \\
7\end{array}$ & 12,549 \\
\hline $\begin{array}{l}\text { Pre-Test } \\
\text { Kontrol }\end{array}$ & 6 & 220 & 248 & $\begin{array}{c}234,8 \\
3 \\
\end{array}$ & 11,089 \\
\hline $\begin{array}{l}\text { Post- } \\
\text { Test } \\
\text { Kontrol }\end{array}$ & 6 & 210 & 241 & $\begin{array}{c}227,6 \\
7\end{array}$ & 11,183 \\
\hline Valid $\mathrm{N}$ & 6 & & & & \\
\hline
\end{tabular}

Berdasarkan tabel 5 diatas diketahui bahwa 6 orang dari 12 jumlah responden yang termasuk Kelompok Eksperimen memiliki nilai rata-rata kadar kolestrol sebelum diberikan perlakuan yaitu 234,33 dengan nilai standar deviasi 11,361. Sedangkan 6 orang dari 12 jumlah responden yang termasuk Kelompok Kontrol memiliki nilai rata-rata kadar kolestrol yaitu 234,83 dengan nilai standar deviasi 11,089 .

Tabel 5: Nilai rata-rata kadar kolesterol pretest

\begin{tabular}{lllll}
\hline $\begin{array}{c}\text { Paired } \\
\text { Samples } \\
\text { Statistics }\end{array}$ & Mean & $\mathrm{N}$ & $\begin{array}{c}\text { Std. } \\
\text { Deviati } \\
\text { on }\end{array}$ & $\begin{array}{l}\text { Std. } \\
\text { Error } \\
\text { Mean }\end{array}$ \\
\hline Pre-Test & 234, & 6 & 11,36 & 4,63 \\
Eksperim & 33 & & 1 & 8 \\
en & & & & \\
\hline Pre-Test & 234, & 6 & 11,08 & 4,52 \\
Kontrol & 83 & & 9 & 7
\end{tabular}

Berdasarkan tabel 6 diatas diketahui bahwa 6 orang dari 12 jumlah responden yang termasuk Kelompok
Eksperimen memiliki nilai rata-rata kadar kolestrol setelah diberikan perlakuan yaitu 216,67 dengan nilai standar deviasi 12,549. Sedangkan 6 orang dari 12 jumlah responden yang termasuk Kelompok Kontrol memiliki nilai rata-rata kadar kolestrol yaitu 227,67 dengan nilai standar deviasi 11,183 .

Tabel 6 : Nilai rata-rata kadar kolesterol posttest

\begin{tabular}{|c|c|c|c|c|}
\hline $\begin{array}{c}\text { Paired } \\
\text { Samples } \\
\text { Statistics }\end{array}$ & $\begin{array}{c}\text { Mea } \\
\mathrm{n}\end{array}$ & $\mathrm{N}$ & $\begin{array}{l}\text { Std. } \\
\text { Devi } \\
\text { atio } \\
n\end{array}$ & $\begin{array}{l}\text { Std. } \\
\text { Error } \\
\text { Mean }\end{array}$ \\
\hline $\begin{array}{l}\text { Post- } \\
\text { Test } \\
\text { Eksperi } \\
\text { men }\end{array}$ & $\begin{array}{c}216 \\
, 67\end{array}$ & 6 & $\begin{array}{l}12,5 \\
49\end{array}$ & 5,123 \\
\hline $\begin{array}{l}\text { Post- } \\
\text { Test } \\
\text { Kontrol }\end{array}$ & $\begin{array}{l}227 \\
, 67\end{array}$ & 6 & $\begin{array}{l}11,1 \\
83\end{array}$ & 4,566 \\
\hline
\end{tabular}

Berdasarkan tabel 7 diatas sebelum dan sesudah diberikan perlakuan pada kelompok kontrol didapatkan nilai ratarata 7,167 dengan standar deviasi 2,317 dan didapatkan nilai $p$ value 0,001, sementara pada kelompok eksperimen didapatkan nilai rata-rata 17,667 dengan standar deviasi 3,266, dan didapatkan nilai $p$ value 0,000 dimana nilai ( $p$ value $\leq 0,05$ ) maka dapat disimpulkan bahwa Ho ditolak dan Ha Diterima, maka dari hasil tersebut ada pengaruh signifikan pada kelompok eksperimen dibanding dengan kelompok kontrol yang tidak diberi perlakuan Latihan Fisik Terstruktur pada pasien Hipertensi.

Tabel 7: Uji Hipotesa

\begin{tabular}{|c|c|c|c|c|c|c|c|c|}
\hline \multirow[t]{2}{*}{$\begin{array}{c}\text { Paired } \\
\text { Sampl } \\
\text { e }\end{array}$} & \multirow[t]{2}{*}{$\begin{array}{l}\mathrm{Me} \\
\text { ad }\end{array}$} & \multirow[t]{2}{*}{$\begin{array}{l}\text { St } \\
\text { d. } \\
\text { De } \\
\text { via } \\
\text { tio } \\
\mathrm{n}\end{array}$} & \multirow[t]{2}{*}{$\begin{array}{c}\text { Std. } \\
\text { Erro } \\
r \\
\text { mea } \\
n\end{array}$} & \multicolumn{2}{|c|}{$\begin{array}{c}95 \% \\
\text { Convidanc } \\
\text { e Interval } \\
\text { of the } \\
\text { Difference } \\
\end{array}$} & \multirow[t]{2}{*}{$\mathrm{t}$} & \multirow[t]{2}{*}{$\begin{array}{l}d \\
f\end{array}$} & \multirow{2}{*}{$\begin{array}{l}\text { Si } \\
\text { g. } \\
\text { (2 } \\
- \\
\text { tai } \\
\text { Ile } \\
\text { d) }\end{array}$} \\
\hline & & & & $\begin{array}{l}\text { Low } \\
\text { er }\end{array}$ & $\begin{array}{c}\text { Up } \\
\text { pe } \\
\text { r }\end{array}$ & & & \\
\hline $\begin{array}{l}\text { Pre- } \\
\text { test }\end{array}$ & $\begin{array}{l}17 \\
, 6\end{array}$ & $\begin{array}{l}3 \\
26\end{array}$ & $\begin{array}{c}1,33 \\
3\end{array}$ & $\begin{array}{c}14,2 \\
39\end{array}$ & $\begin{array}{l}21 \\
, 0\end{array}$ & $\begin{array}{l}13 \\
, 2\end{array}$ & 5 & $\begin{array}{l}0 \\
00\end{array}$ \\
\hline $\begin{array}{l}\text { Ekspe } \\
\text { rimen } \\
\text {-Post- } \\
\text { test } \\
\text { Ekspe } \\
\text { rimen }\end{array}$ & 67 & 6 & & & 94 & 50 & & \\
\hline
\end{tabular}




\section{b. Pembahasan}

\section{Kadar Kolestrol Sebelum Dilakukan Latihan Fisik Terstruktur}

Berdasarkan hasil penelitian menunjukkan bahwa 12 orang dari 15 responden yang terbagi 2 menjadi kelompok eksperimen dan kelompok kontrol didapatkan nilai rata-rata kadar kolestrol sebelum diberi perlakuan yaitu pada kelompok eksperimen memiliki nilai rata-rata kadar kolestrol yaitu 234,33 dengan nilai standar deviasi 11,361. Sedangkan pada Kelompok Kontrol memiliki nilai ratarata kadar kolestrol yaitu 234,83 dengan nilai standar deviasi 11,089. Pada tabel ini menunjukkan bahwa adanya peningkatan kadar kolestrol sebelum dilakukan Latihan Fisik Terstruktur di Rumah Sakit Grandmed Lubuk Pakam, hal ini diketahui pada saat peneliti melakukan observasi pada pasien Hipertensi yang sedang di rawat inap.

Hal ini sejalan dengan penelitian yang dilakukan oleh Aristoteles (2018) yang berjudul Pengaruh Latihan Fisik Aerobik Terhadap Kadar High Density Lipoprotein (HDL) yang menyatakan bahwa penyebab kolestrol (HDL) yang rendah salah satunya adalah kurang gerak badan. Olahraga dapat mengakibatkan otot dan rangka tubuh bergerak, terjadinya peningkatan denyut jantung sehingga darah, oksigen dan nutrisi dapat disalurkan ke seluruh tubuh dengan baik. Jarang melakukan berolahraga dapat mengakibatkan distribusi oksigen keseluruh tubuh kurang. Akibatnya akan terjadi kekurangan oksigen di otot, sehingga badan terasa kaku dan pegal.

Kadar kolestrol dalam tubuh adalah satu hal yang sangat penting dalam menetukan seseorang terkena penyakit pembuluh darah jantung.

\section{Kadar Kolestrol Setelah Dilakukan Latihan Fisik Terstruktur \\ Berdasarkan hasil penelitian} menunjukkan bahwa 12 orang dari 15 responden yang terbagi 2 menjadi kelompok eksperimen dan kelompok kontrol didapatkan nilai rata-rata kadar kolestrol setelah diberi perlakuan yaitu pada kelompok eksperimen memiliki nilai rata-rata kadar kolestrol yaitu 216,67 dengan nilai standar deviasi 12,549 . Sedangkan pada Kelompok Kontrol memiliki nilai rata-rata kadar kolestrol yaitu 227,67 dengan nilai standar deviasi 11,183 . Pada tabel ini menunjukkan bahwa adanya penurunan kadar kolestrol secara signifikan setelah dilakukan Latihan Fisik Terstruktur di Rumah Sakit Grandmed Lubuk Pakam, hal ini diketahui pada saat peneliti melakukan observasi pada pasien Hipertensi yang sedang di rawat inap.

\begin{tabular}{lll}
\multicolumn{1}{c}{ Latihan } & \multicolumn{1}{c}{ Fisik } & \multicolumn{2}{c}{ Terstruktur } \\
(Olahraga) secara rutin dapat \\
mengurangi & terjadinya stres dan
\end{tabular} terjadinya penurunan berat badan, serta pembakaran lemak dalam darah, dan memperkuat otot jantung.

\section{Pengaruh Latihan Fisik Terstruktur Terhadap Penurunan Kadar Kolestrol Pada Pasien Hipertensi Di Rumah Sakit Grandmed Lubuk Pakam.}

Berdasarkan data di atas diperoleh nilai rata-rata kadar kolestrol pada pasien Hipertensi sebelum diberi perlakuan yaitu 234,33 dengan nilai standar deviasi 11,361 dan nilai ratarata kadar kolestrol setelah diberi perlakuan yaitu 216,67 dengan nilai standar deviasi 12,549 dengan jumlah responden 12 orang dari 15 sampel yang dilakukan observasi pengukuran kadar kolestrol pada saat terapi Latihan Fisik terstruktur di Rumah Sakit Grandmed Lubuk Pakam tahun 2021 dan hasil uji statistik pada kelompok 
eksperimen dapat diketahui nilai $p$ value $=0,000$ ( $p$ value $\leq 0,05)$ maka Ho ditolak dan $\mathrm{Ha}$ diterima, jadi dapat diketahui bahwa ada pengaruh Latihan Fisik Terstruktur terhadap penurunan kadar kolestrol pada pasien hipertensi di Rumah Sakit Grandmed Lubuk Pakam tahun 2021.

Hal ini sejalan dengan dengan penelitian yang dilakukan oleh Suwarsi (2017) dengan judul Penurunan Kadar Kolestrol Darah Pada Kelompok Lansia Yang Diberikan Terapi Aktivitas Fisik Di Desa Wedomartani Sleman didapati hasil bahwa terapi aktivitas fisik efektif dalam menurunkan kadar kolestrol darah pada lansia yang mengalami hiperkolestrolemia. Terapi aktivitas fisik merupkan bagian dari terapi modalitas, yang merupakan metode pemberian terapi menggunakan kemampuan fisik atau elektrik. Terapi modalitas menurut National center for complementary alternative Medicine adalah terapi manipulative yang berbasis tubuh.

Aktivitas olahraga juga salah satu yang mempengaruhi kadar kolestrol total daluham darah. Aktivitas olahraga adalah kondisi natural yang dibutuhkan manusia. Daya tahan tubuh akan semakin meningkat seiring meningkatnya aktivitas olahraga yang dilakukan. Aktivitas olahraga seperti berjalan kaki, jalan cepat, lari-lari kecil, senam jantung sehat, bersepeda dan kegiatan olahraga yang bersifat tidak kompetisi dan tidak berlebihan akan memperkuat kerja jantung dan mengurangi resiko kolestrol tinggi. Aktivitas olahraga yang dilakukan secara rutin akan meningkatkan kadar HDL dan menurunkan kadar LDL, dengan begitu kadar kolestrol total dalam darah akan seimbang (Susanto, 2010).

Setiap pasien diteliti 2 kali, sebelum dilakukan terapi dan 3 hari setelah dilakukan terapi Latihan Fisik Terstruktur. Latifan fisik dilakukan sebanyak 3 kali yang terdiri dari hari pertama Senam (20-30 menit), hari ke 2 Jalan kaki (20-30 menit), dan hari ke 3 Senam (20-30 menit). Hasil penelitian ini menunjukkan hasil yang signifikan bahwa pasien mendapatkan terapi Latihan Fisik Terstruktur selama 3 hari menunjukkan penurunan kadar kolestrol secara signifikan dibandingkan dengan pasien yang tidak diberi terapi Latihan Fisik Terstruktur.

\section{Kesimpulan}

Hasil penelitian pada kelompok eksperimen nilai $p$ value $0,000 \leq 0,05$ dan pada kelompok kontrol nilai $p$ value $0,001 \leq 0,05$ sehingga dapat disimpulkan bahwa ada Kelompok eksperimen memberikan hasil pengaruh lebih baik dibandingkan dengan kelompok kontrol Pada Pasien Hipertensi.

Hasil uji statistik yang telah dilakukan menunjukkan adanya hasil yang signifikan sehingga dapat disimpulkan adanya Pengaruh Latihan Fisik Tertruktur Terhadap Penurunan Kadar Kolestrol Pada Pasien Hipertensi.

\section{Ucapan Terima Kasih}

Ucapan terima kasih disampaikan kepada Insitut Kesehatan Medistra Lubuk Pakam dan Rumah Sakit Grandmed Lubuk Pakam yang membantu pendanaan dalam melaksanakan proses pengabdian masyarakat.

\section{Daftar Pustaka}

Arikunto, Suharsimi. (2010). Prosedur Penelitian Suatu Pendekatan Praktek. Jakarta: Rineka Cipta.

Aristoteles. (2018). Pengaruh Latihan Fisik Aerobik Terhadap Kadar High Density Lipoprotein (HDL). Jurnal ilmiah Multi science kesehatan, Vol 9, No 2

Arwani, Nurhayati dan Purnomo. (2013). Perbedaan Keseimbangan 
Received: 28 May 2021 :: Accepted: 12 June 2021 :: Published: 30 June 2021

Tubuh Lansia Berdasarkan Keikut Sertaan Senam Lansia Di Panti Werda Pelkris Pengayoman Dan Elim Semarang. Journal balance of body, gymnastics elderly. vol.6, no. 1 .

Hidayat, S. S. dkk. (2015). Panduan Penulisan Skripsi Sarjana. Edisi Revisi. Bandung: Fakultas Psikologi Universitas Kristen Maranatha.

Kemenkes RI. (2017). Ayo Bergerak Lawan Obesitas. Jakarta: Kementrian Kesehatan RI

Lanawati. (2015). Hubungan Antara Senam Kesegaran Jasmani Dengan Fungsi Kognitif Dan Keseimbangan Tubuh Di Posyandu Lansia Desa Dauh Puri Kauh Denpasar. Bali: Universitas Udayana.

Putri I A, Kaunang W P J, dan Kepel B J. (2016). Hubungan Antara Aktivitas Fisik, Kebiasaan Merokok, Dan Riwayat Keluarga Dengan Kejadian Hipertensi Pada Pasien Rawat Jalan Di Poliklinik Intera Rumah Sakit Umum Daerah Bitung. Manado: Universitas Samratulangi.

Rahadiyanti, Ayu. dkk. (2015). Asupan Makan Dash-Like Diet Untuk Mencegah Risiko Hipertensi Pada Wanita Rediabetes. Semarang. Jurnal Klinik Indonesia

Sugiyono. (2012). Metode Penelitian Kuantitatif Kualitatif Dan R\&B. Bandung. Alfabeta

Sumaryoto dan Nopembri, S. (2017). Buku Guru Pendidikan Jsmani, Olahraga, Dan Kesehatan Untuk SMA/MA/SMK/MAK KELAS XI. Edisi revisi. Jakarta. Pusat Kurikulum dan Perbukuan, Balitbang, Kemendikbud.

Susanto. (2010). Hindari Hipertensi, Konsumsi Garam 1 Sendok Per Hari. Jakarta: Gramedia.
Suwarsi. (2017). Penurunan Kadar Kolestrol Darah Pada Kelompok Lansia Yang Diberikan Terapi Aktivitas Fisik Di Desa Wedomartani Sleman. Jurnal Keperawatan Respati Yogyakarta.

Triyanto E. (2014). Pelayanan Keperawatan Bagi Penderita Hipertensi Secara Terpadu. Yogyakarta: Graha Ilmu.

Widianti, Anggriyana Tri dan Atikah Proverawati. (2010). SENAM KESEHATAN. Yogyakarta: Nuha Medika.

Wijaya A S, dan Putri Y M. (2013). Keperawatan Medikal Bedah. Yogayakarta: Nuha Medika.

Yovina. 2012. KOLESTROL. Yogyakarta: Pinang Merah Publisher

Yuliana, S. Pelatihan Kombinasi Core Stability Dan Ankle Strategy Exercise Tidak Lebih Meningkatkan Dari Core Stability Exercise Untuk Keseimbangan Statis Pada Mahasiswa S1 Fisioterapi Stikes Aisyiyah Yogyakarta. Denpasar Universitas Udayana. 